\title{
LEAN AUTOMATION FOR LOW-VOLUME MANUFACTURING ENVIRONMENT
}

\author{
Tatyana Karaulova, Konstantin Andronnikov, \\ Kashif Mahmood \& Eduard Shevtshenko
}
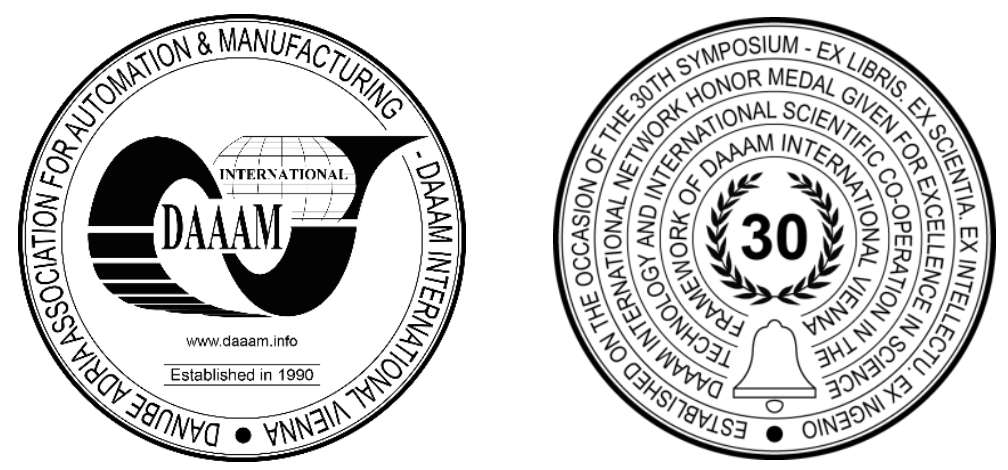

This Publication has to be referred as: Karaulova, T[atyana]; Andronnikov, K[onstantin]; Mahmood, K[ashif] \& Shevtshenko, E[duard] (2019). Lean Automation for Low-Volume Manufacturing Environment, Proceedings of the 30th DAAAM International Symposium, pp.0059-0068, B. Katalinic (Ed.), Published by DAAAM International, ISBN 9783-902734-22-8, ISSN 1726-9679, Vienna, Austria

DOI: $10.2507 / 30$ th.daaam.proceedings.008

\begin{abstract}
In most cases, the complexity of installation work, such as the induction of a collaborative robot at metal-working enterprises exceeds the complexity of machining and significantly exceeds the labour costs for all other types of production. Today the most assembly jobs in the manufacturing domain of Small and Medium-sized Enterprises (SMEs) are still performed by hand due to high mix and low volume orders. The interaction of humans and robots may increase the efficiency in complex assembly processes. The flexibility and variability of assembly processes require close cooperation between the worker and the automated production system. Automation of production is not an easy process for an enterprise, which requires high investment and additional skills, but it is necessary to improve working conditions and product quality. This article provides an efficiency analysis of collaborative robots usage in one of the Estonian enterprise.
\end{abstract}

Keywords: Lean Automation; Collaborative robot (cobot); Human Robot Collaboration (HRC); Cyber Physical Production Systems (CPPS); Process analysis.

\section{Introduction}

\subsection{Motivation for research}

The aim is to investigate the potential of routine work automation in one of the Estonian electronic factories; to analyse the efficiency of using the cobots and their influence on the availability of resources; to perform a cost-benefit analysis, and to bring out the best world practices. Today the most assembly jobs are still performing manually due to the following reasons.

- wide variety of product variants;

- small batch sizes;

- shorter product lifecycles. 
These reasons apply particularly to small and medium-sized enterprises (SMEs). Automation is not cost-effective in this situation, because small production runs do not lend themselves to reasonable payback periods.

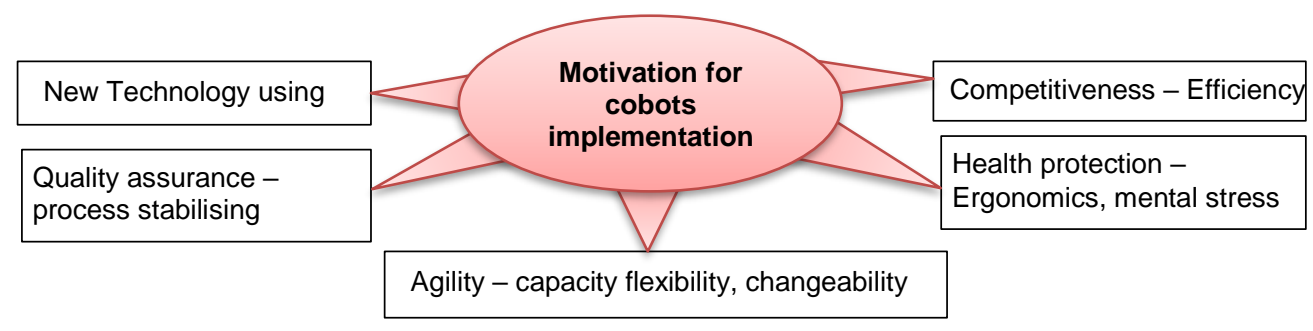

Fig. 1. The motivation for cobots implementation in enterprises with low-volume production

Flexibility and changeability of assembly processes require a close linkage between the worker and the automated assembly system. The interaction between human and robot improves complex assembly processes, mainly when a robot can be guided by a worker and provides power assistance to the worker.

The close linkage of human and machine in cooperative assembly tasks should make use of the strengths of both sides. Typically an automated assembly system provides a couple of advantages such as operation without breaks and fatigue and high productivity for simple assembly tasks. Though, the flexibility of automated systems such as robots is usually restricted due to high programming effort and limited abilities for the handling of complex or limp parts. On the other hand, a human provides exceptional sensomotoric abilities for the complex handling tasks, can quickly adapt to new process sequences but have a limitation of precision. Cooperative work stations combine the advantages of a human and an automated robotic system [1].

Recently, Human-Robot Collaboration (HRC) has got plenty of attention as robotic systems have already become essential components in various industrial sectors. HRC provides relief to human workers from heavy tasks by establishing communication channels between humans and robots for better overall performance [2]. Ideally, an HRC team should work similarly as a human-human collaborative team in a manufacturing environment. However, timeseparation or space-separation is dominant in HRC systems, which reduced productivity for both human workers and robots.

Humans and robots can work safely together, side by side on the production floor. For many companies, collaborative robotics is becoming a current strategy. As much as collaborative robots (cobots) - which are designed to share a workspace with humans, have been a game-changing force over the past few years, industrial robots have certainly held their position in the industry, as evidenced by the most recent Robotics Industries Association report [3]. The rise of the cobot, however, created a new set of questions for end users. Whereas end users previously only had to determine the best industrial robot for an application, they now have to decide whether an industrial robot or cobot is best suited for the job [4].

\subsection{Lean Automation}

Lean Automation is the adoption of Evolving Smart Automation Concepts in the world. The lean concepts/technologies are helping manufacturers to improve their quality, productivity and maintainability. Lean automation applies lean concepts in situations, where manual processes are best, and to balance them with the application of technology when the use of technology makes sense. Firstly, companies must define their processes, how they can be simplified, and to figure out the equipment need [5]. Nowadays, there are new areas of application for Lean Automation due to the potential of Industry 4.0 technologies. For example, by implementing flexible, powerful and affordable Cyber Physical Systems (CPS) [6]. CPS can be generally characterised as "physical and engineered systems whose operations are monitored, controlled, coordinated, and integrated by a computing and communicating core" [7]. CPS covers such diverse disciplines as transport, infrastructure, health care, emergency response, defence, energy, or manufacturing.

Cyber Physical Production Systems (CPPS) can be recognised as a more specific concept that is geared to manufacturing [8]. CPPS consist of autonomous and cooperative elements and systems across all levels of production. The main benefits of CPPS are [9]:

- Optimisation of production processes;

- Optimised product customisation;

- Resource-efficient production;

- Human-centred production processes.

The major benefit of embracing CPPS can be recognised as future production systems, which are accepted by the large markets in the next few years. Industry 4.0 prompts the reorganisation of production systems with flexible, 
collaborative workcells. "A workcell is an arrangement of resources in a manufacturing environment to improve the quality, speed and cost of the process. Workcells are designed to improve these indicators by improving process flow and are based on the principles of Lean Manufacturing" [10], [11].

\subsection{Low-volume manufacturing}

The benefits of robotic automation for high-volume manufacturing are well recognised and understood. Machinetending robots used in these production schemes do not need to be very flexible, as they may load and unload one type of part for hundreds of thousands of times. However, this lack of flexibility avoids enterprises to adapt those frequent changeovers, and small batch sizes, what has hindered robotic automation's integration into contract shops [12]. The main concern in low-volume production or bespoke processes is the uncertainty about the suitability of robots. In most cases, the arguments against using robots as an alternative solution between multiple tasks of the processes tend to focus on the perceived operational and financial difficulties. Following are the reasons that reflects the industrial robots are not suitable for low-volume production [13]:

- It is more difficult and costly to change process;

- High speeds and throughput are not needed for low-volume processes;

- $\quad$ Fixed work cells may require changes to the production floor layout;

- May require specialised personnel or outsources resources for set up, program and maintain.

The initial implementation costs of industrial robots can be similar to collaborative robots, but if a safety cell is required, it will add system integration costs.

\section{Collaborative robots integration to production}

"A common misconception is that introducing robots leads to replacing of manual labour. Instead, consideration should be given to how much additional low volume processes could be handled by combining robotic and manual labour, rather than on using robots to handle everything. A robot should not be seen as a replacement for labour, but rather as a way of increasing its efficiency. In this regard, a robot becomes a tool that a person can use to achieve bespoke products, which would not be possible without it or as a way to release labour resources to perform other tasks"[14].

Humans can easily put very complicated things together. In contrast, robots can perform simple tasks accurately. The flexible production system combines these human and robot cooperation characteristics to enable the efficient production of a variety of products [15]. The number of tasks in which humans and robots combine their skills in collaborative work are increasing. The cobots concept is developed to use human and robot cooperation in a shared workspace. "The assembly operation market share is forecasted to overgrow during the period, shown in Fig. 2. Collaborative robots find their applications in the manufacturing industry as these robots allow the new user to grasp the basics of working easily. Collaborative robots are known for reducing the time of assembly due to their accuracy, speed, reach, and any material handling capacity" [16].

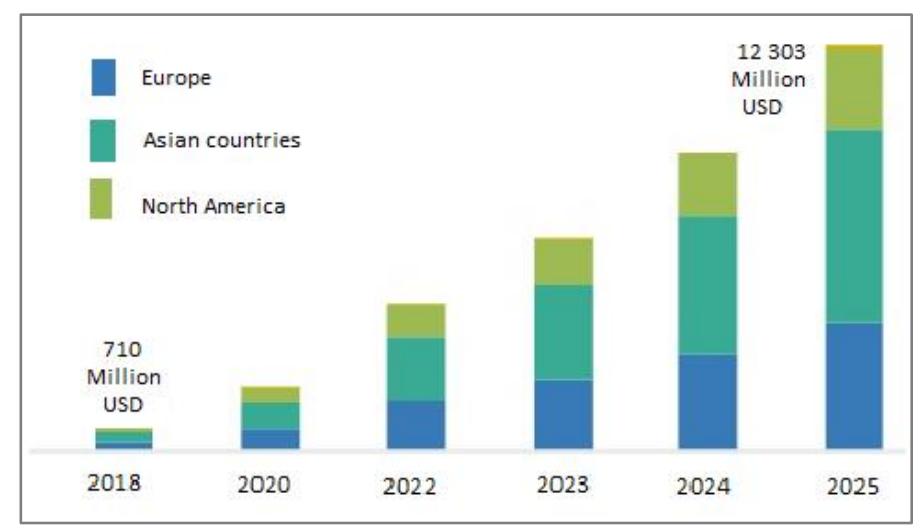

Fig. 2. Collaborative robot market [16]

Most importantly, the cost of adopting robotic solutions to a given problem has been reduced significantly with the introduction of cobots. A typical cobot system now costs around $€ 30 \mathrm{~K}$, which is relatively affordable to most small and medium-sized enterprises (SMEs). Due to the lower initial investment and a shorter payback period, the adoption rate acceleration is expected [17]. Product flexibility, several variants, production volume, product size, and batch plays a 
significant role in the choice between manual, automatic, or collaborative production [18]. Fig. 3 illustrates the new role of cobots in the manufacturing process.
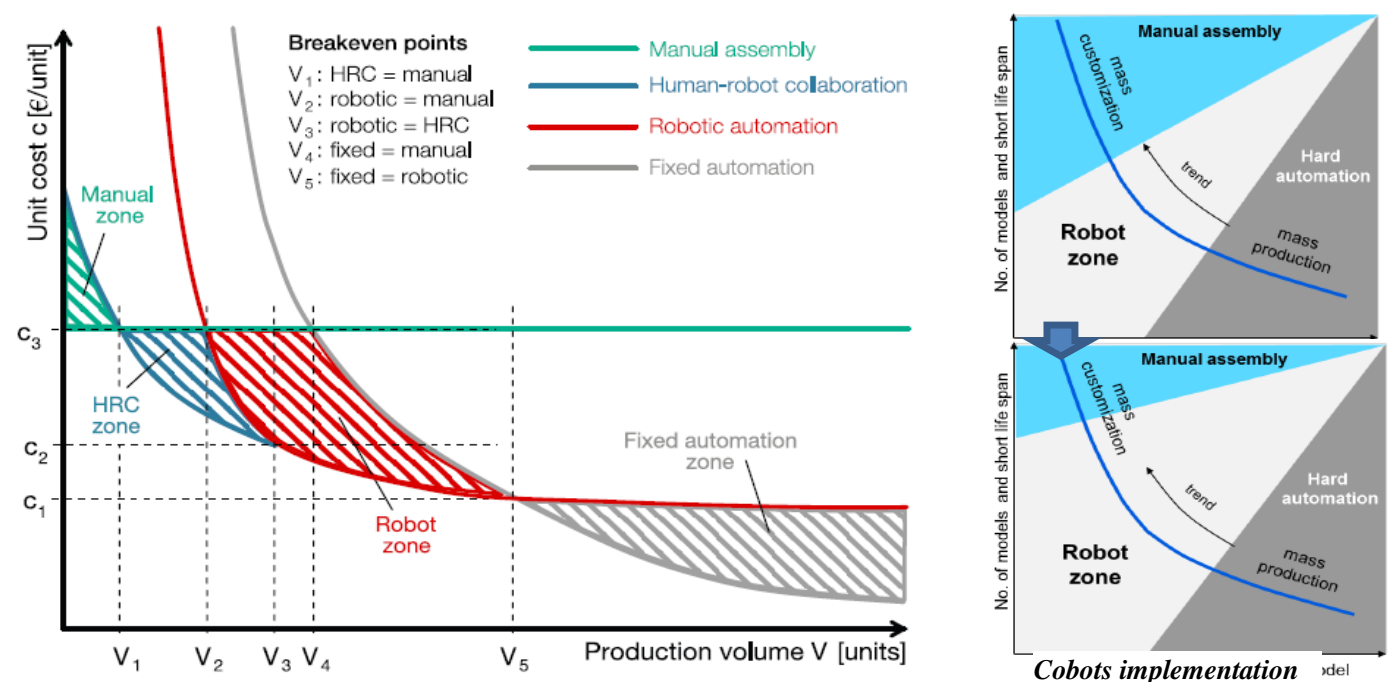

Fig. 3. Economic comparison of alternative production systems [17]

Collaborative robots are fulfilling the processes that traditionally performed by human operators [19]. Therefore they must have security devices to detect and react to human contact before actual physical contact or work with such a small force that even in case of collision, there is no unacceptable risk of labour injury.

ISO 15066 standard advises on human-robot co-operation safety issues. These are recommended for the development of robot cell solutions [20], [21], [22]. The general rules of safety are applied when the industrial robot immediately stops, when someone enters his workspace. By standard, the safety workspace is divided into two parts: robot workspace (operating space); and collaborative workspace.

Collaborative robots are defined by ISO 10218, which defines four main collaborative robot features: Safety monitored stop, speed and separation monitoring, power and force limiting, and hand guiding. Advantages and disadvantages of collaborative robots [23] are shown in Fig. 4.

1. Can typically share a workspace with employees;

2. Relatively simple to program and integrate;

3. Return on investment can be usually achieved in less than a year.

4. Easier to install and configure (robots weigh about $30 \mathrm{~kg}$, you only need a 220v outlet)
1. Risk assessment is required to define need for safety measures;

2. Safety regulations can result in very low operating speeds or multiple stops. Significantly increase integration costs;

3. Limited reach, payload, speed and accuracy;

4. Operators are still required in a collaborative work cells .

Fig. 4. Collaborative robots advantages and disadvantages

Human-robot collaboration offers significant potential for improving work organisation. This creates an opportunity to change manual assembly work that has previously tended to be monotonous. The common motivation for using the cobots are [24]:

- Increase operational efficiency

- Try out innovative technology

- Improve ergonomics

- Reduce monotony

- Increase flexibility regarding batch sizes

- Reduce assembly time

\section{Collaborative robots implementation in production enterprise}

Implementation of automation to an enterprise needs rigorous analysis. Steps for cobots implementation into a production environment are suggested in the current research, as shown in Fig 5. 
Goal: The posibility of cobots implementation in the production

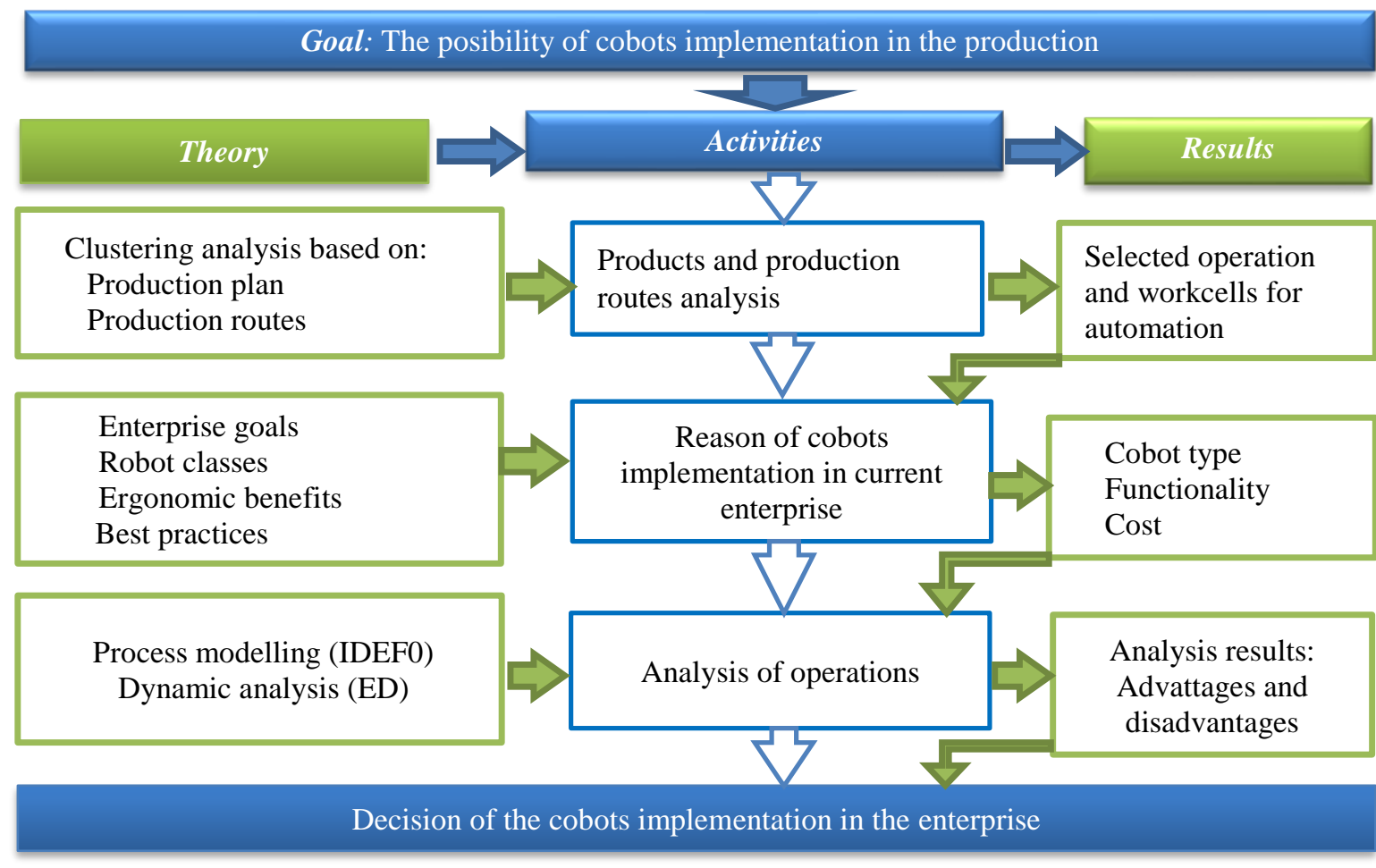

Fig. 5. The framework of collaborative robots introduction into production

\subsection{Products and production routes analysis}

A data analysis stage is the first step of the developed framework for processes automation. Clustering is an automatic splitting of objects set into groups according to the principle of similarity. General clustering scheme includes the following steps: characterization $\rightarrow$ grouping of objects $\rightarrow$ presentation of results.

Each production route represents a unidirectional flow, which could not be changed. Routings of manufactured items are required for the definition of the groups of machines based on similarity analysis. Askin \& Standridge have formulated the steps of the basic similarity analysis [25]:

- Identify items that are produced with the same processes / the same equipment

- Include those items into a part family

- Group into a cell in order to minimise material handling.

An example of cluster analysis is proposed in the article "Work-Cells Concept Development for High Mix Low Volume Market Conditions" [26]. In the current research, authors have identified operations that require the highest accuracy of execution and analysed if the operation was often used, heavy or too monotonous for the operator. The target was to release people from highly repetitive tasks or tasks that require a high level of precision, which is beyond the capabilities of an operator.

For production under high mix and low volume conditions, the process of cobots integration is rather laborious. Therefore, it is usually carried out by the recommendation of the company's management according to the production plan. As a result, the current analysis are executed on the selected work cells operations for collaborative robots implementation.

\subsection{Reasons of cobots implementation in current enterprise}

The decision about collaborative robots applying in a specific case depends on enterprise goals. Usually, robots perform assembly tasks significantly slower than human workers because cage-free operation puts constraints on their maximum speeds. In addition, a robot can generally be equipped with only one tool or one specific gripper, which can be used to hold one specific part. That somewhat limits the tasks robots can take over from humans, and that can result in potential savings.

It is, therefore, necessary to consider the robot's higher performance capabilities. The savings that can be potentially achieved by a robot taking over an assembly process from a human worker for a specified period are relatively low. The use of cobots requires an alternative justification (e.g. ergonomics), or longer running times (e.g. three-shift operation) to 
achieve adequate levels of operational efficiency in a traditional sense. Table 1 shows the comparison of the capabilities for collaborative robots and human.

\begin{tabular}{|l|l|}
\hline \multicolumn{1}{|c|}{ Collaborative Robot } & \multicolumn{1}{c|}{ Human } \\
\hline $\begin{array}{l}\text { Can use sensors to "see" certain trained things } \\
\text { (camera, laser scanner, light curtain, pressure mat) }\end{array}$ & $\begin{array}{l}\text { Use eyesight to see and brain to understand what they are } \\
\text { seeing }\end{array}$ \\
\hline $\begin{array}{l}\text { Can limit forces imparted to the environment by } \\
\text { programmed means }\end{array}$ & $\begin{array}{l}\text { Can apply a gentle touch first to understand how to use } \\
\text { contact forces to acquire or position parts }\end{array}$ \\
\hline $\begin{array}{l}\text { Specific process switches and other inputs can be } \\
\text { used to make decisions }\end{array}$ & Use other senses available -hearing, taste, smell \\
\hline Strong and never tired & Relatively weak and prone to repetitive stress injury \\
\hline Can be moved and explicitly re-programmed & Very flexible, easy to redeploy with minimal instruction \\
\hline Can be pre-programmed to handle process variation & Handles process variation well \\
\hline Highly precise positioning & Imprecise \\
\hline Can be explicitly programmed for assembly & People are naturally good at assembly \\
\hline
\end{tabular}

Table 1. Comparison of human and collaborative robot characteristics

One of the goals of using cobots in the industry is to unlock ergonomic benefits and to minimise existing deficiencies, providing support in situations where workers must maintain a specific posture or hold themselves in an awkward position, e.g. unnatural postures, uncomfortable reaching distances. The ergonomic improvements are the key reasons for deploying lightweight robots. On the other hand, optimised ergonomics of human-robot systems does not mean improvements in financial performance indicators.

Human Robot Collaboration is suitable for performing complex operations, but the level of human errors due to fatigue or lack of experience is quite high. Conversely, robots are suitable for performing repetitive operations and gruelling and heavy tasks, facilitating operator fatigue. The final joint actions of these two actors determine the overall performance of the work item and ergonomics analysis [27].Fig. 6 introduces fatigue level comparison between manual and HRC tasks [28]. The time reduction in the manual operations through HRC have beneficial effect on the working conditions since the achievement of the production goals requires less human effort.

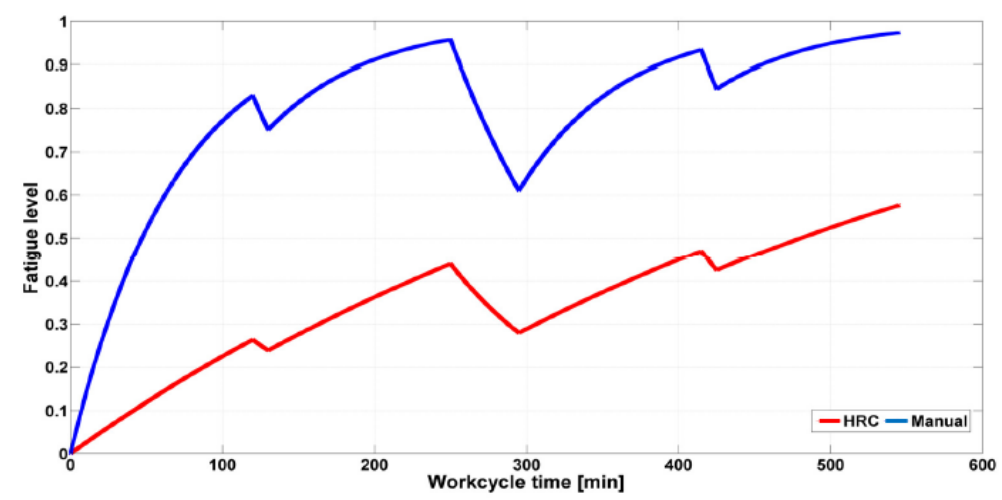

Fig. 6. Fatigue level comparison between manual task (red line) and HRC task (blue line) [28]

In a case study of the current research, we focus on a product labelling process, which is usually applied for all products of the enterprise. The labelling station has simple operations; human tasks are monotonous and do not require a high level of mental skills, which is the first prerequisite for a successful cobot integration.

\subsection{Analysis of current labelling operation}

The current study scope includes the marking process and does not consider the material supply to the workstation. Authors have observed the current state of the labelling work-cell, followed by filming and analysis of typical work procedures. Personnel and management were interviewed to get insight into the possible problems they face in daily work on this workstation. Based on the collected information, the underlying problems were defined. Today, the marking process is carried out manually; it is a routine work with a wide variety of different details types. The process could be described as follows (see figure 7):

Step 1. An employee takes detail from the box and put it on the conveyor. 
Step 2. Marking process performs automatically when details are passing underneath the printer. Step 3. After marking, detail falls from the conveyor into the empty box.
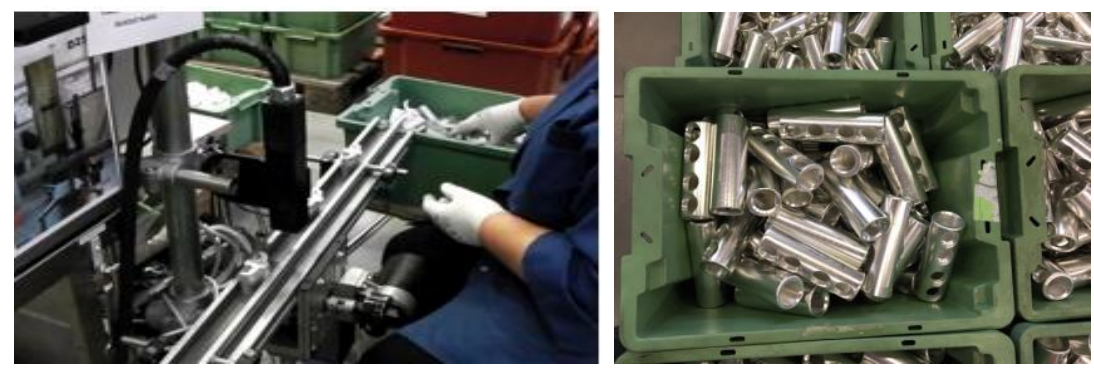

Fig. 7. Current product and process view.

To make improvements to the production processes, it is crucial to understand how the process is currently working. Authors suggests using the IDEF0 (Integration Definition for Function Modelling) method for this purpose. It is a standard modelling technique for the analysis, development, re-engineering, and integration of information systems and business processes.

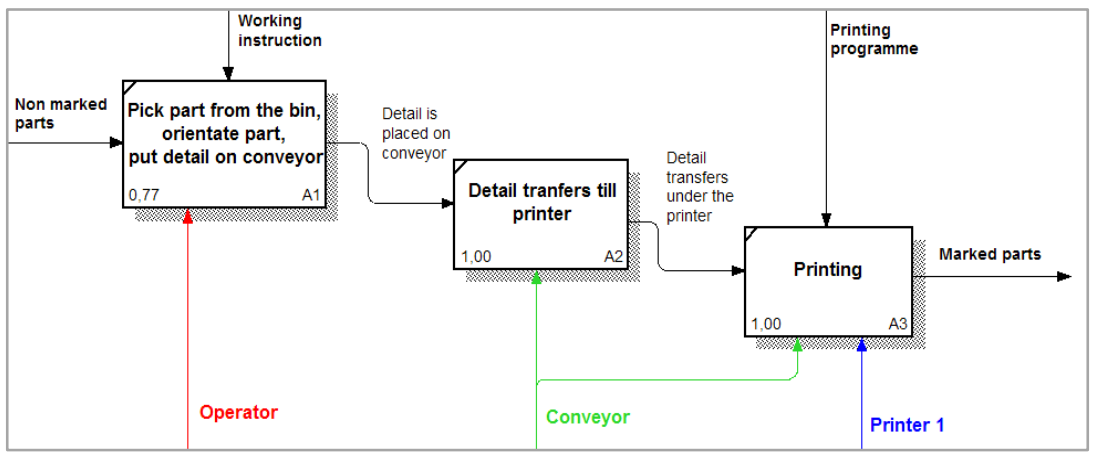

\begin{tabular}{|c|c|}
\hline Activity Name & $\begin{array}{l}\text { Duration } \\
\text { (Seconds) }\end{array}$ \\
\hline Marking process & 2,77 \\
\hline $\begin{array}{l}\text { Pick part from the bin, } \\
\text { orientate part, put } \\
\text { detail on conveyor }\end{array}$ & 0,77 \\
\hline $\begin{array}{l}\text { Detail tranfers till } \\
\text { printer }\end{array}$ & 1,00 \\
\hline Printing & 11,00 \\
\hline
\end{tabular}

Fig. 8. IDEF0 model and report of the current process.

The operation time for labelling one box of products (70 pcs.) was observed. It is the only operating time (OT). The analysis has done for OT; later, it was compared with the time a collaborative robot needs for performing the same operation. The activity time is shown in the right section in figure 8. Authors researched from which elements are included in the operator's work time, as shown in Fig 9., and discovered that the cobot could work without any allowances.

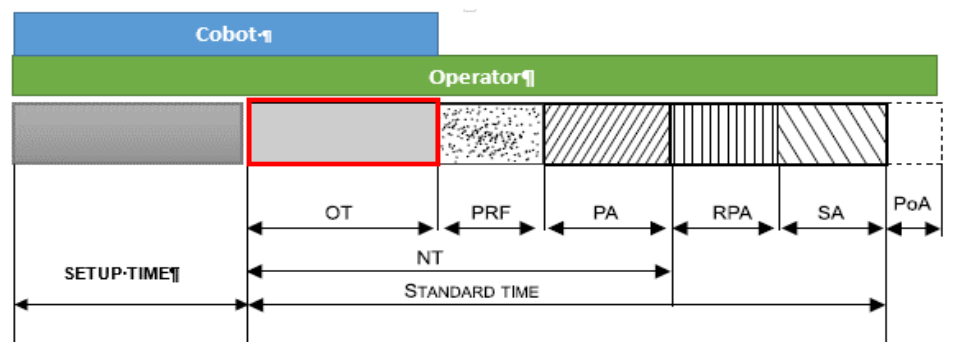

$\begin{array}{rll}\text { OT } & - & \text { Observed Time } \\ \text { PRF } & - & \text { Performance Rating Factor } \\ \text { NT } & - & \text { Normal Time } \\ \text { PA } & - & \text { Process Allowances } \\ \text { RPA } & - & \text { Rest and Personal Allowances } \\ \text { SA } & - & \text { Special Allowances } \\ \text { PoA } & - & \text { Policy Allowances }\end{array}$

Fig. 9. Components of time [adopted from 29]

Model time based dynamic analysis is illustrated in Fig 10. Authors discovered that an operator is loaded about $92 \%$ and he is working in a non-stop mode. It is too much and leads to quick operator fatigue.

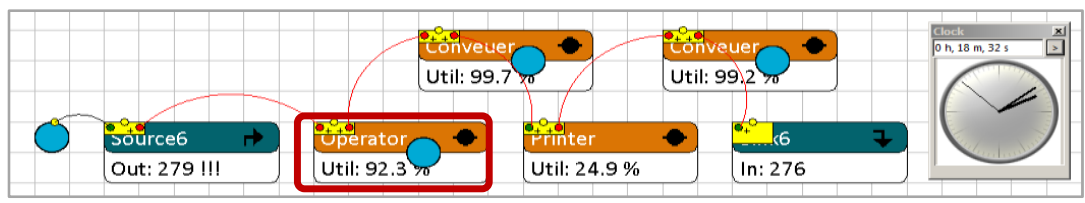

Fig. 10. Dynamic analysis of the current process in Enterprise Dynamics system. 
Based on Mark Lewandowski [30] definition that cobots provide value and succeed when the following conditions met:

- $\quad$ Speed is 6-8 cycles per minute

- Low payload - less than 10kg typically

- Little or no robotics expertise available

- Processes/Machinery with Low Utilization

- Processes previously seen as uneconomical or too complex where partial automation might be feasible or desirable.

The labelling work-cell is suitable working cell for cobot integration; it requires the frequent involvement of operator - utilisation is $92.3 \%$, low machinery utilisation - printer utilisation - $24.9 \%$, and high variability of labelled parts.

\subsubsection{Robot choice}

For the current case study, in coordination with the company, Pickit company robot Pick-it M-HD [https://www.pickit3d.com/product/pick-it-m-hd] was selected, which ensuring simple set-up, reliable operation, smooth user experience, easy programming, and low-risk integration. The Pick-it M-HD camera and software finds small to medium object in bins, tables and boxes and tells the robot where and how to pick them. Pick-it M-HD is the perfect solution for almost any picking application due to to the following value-adding [31] features: highly accurate, high resolution, reliable and fast, and works with any material.

Parts for testing were sent to the Pickit company to prepare a video of the labelling operation produced by cobot, see Fig. 11. Based on this video, the new process with some corrections of the line construction was developed.
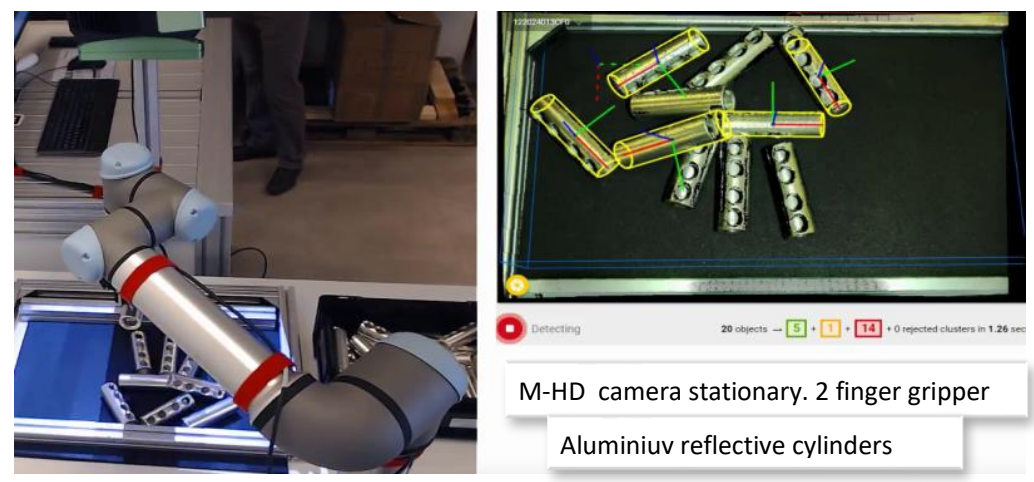

Fig.11. Labelling operation by using cobot [https://drive.google.com/open?id=1b3DHcJqtvDMLi515FjD8DI17zyeyYULX]

\subsection{Analysis of automated labelling operation}

The purpose is to develop a collaborative work station to perform marking operations, which are performed manually today. Another purpose is to make a showcase of new technology and influence others to adapt it for another process in the future.

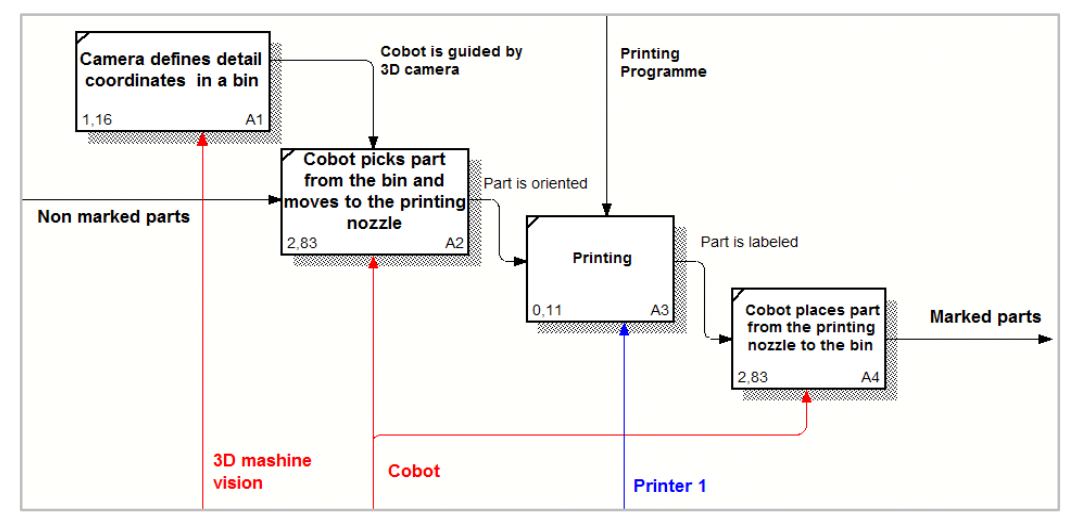

\begin{tabular}{|c|c|}
\hline Activity Name & $\begin{array}{l}\text { Duration } \\
\text { (seconds) }\end{array}$ \\
\hline Marking process & 6,93 \\
\hline $\begin{array}{l}\text { Camera defines detai1 } \\
\text { coordinates in a bin }\end{array}$ & 1,16 \\
\hline $\begin{array}{l}\text { cobot picks part from } \\
\text { the bin and moves it to } \\
\text { the printing nozzle }\end{array}$ & 2,83 \\
\hline Printing & 0,11 \\
\hline $\begin{array}{l}\text { Cobot places part from } \\
\text { the printing nozzle to } \\
\text { the bin }\end{array}$ & 2,83 \\
\hline
\end{tabular}

Fig. 12. IDEF0 model and report of the future process.

The requirements for process changing are: 
- Details should be picked from the default plastic boxes used in a factory;

- The workstation should not occupy more space than it currently occupies;

- Takt time should be enough to cover another workstations demand.

The functional analysis of the processes as shown in Fig.8 and Fig 12, operation time (OT) for labelling of 1 part with the robot integrated process is longer than manual: for manual work was $2.77 \mathrm{sec} / \mathrm{pcs}$, with collaborative robot direct printing without conveyor is $6.93 \mathrm{sec} / \mathrm{pcs}$. The difference in time arises since when using cobots, the orientation of the part is required before installation on the conveyor.

If we compare the operational time of labelling work-cell with cobot, it is two and half times slower than human, so, to fulfil the demand in marked parts, cobot should work two and a half shifts to match the efficiency of a human worker. However, if we apply allowances to human work time (about 15\%, see Fig.9), lunch, meetings and rest, the operational time difference between human and cobot is decreasing. Besides of all, one cobot operator can serve several labelling workplaces. The primary function of an operator in a collaborative work environment is to deliver the boxes with parts to the work-cell. Also, the printer changeover for the new product required a considerable set-up. In the future, after cobots implementation on all labelling machines, one person will be able to perform machines set up and to arrange material supply from/to the warehouse. To calculate the rationality of investment into an automated solution, it was necessary to define the costs for both scenarios: usage of human resources and the application of the robotic solution.

\begin{tabular}{|l|l|l|}
\hline & \multicolumn{1}{|c|}{ Current state } & \multicolumn{1}{c|}{ Forecast } \\
\hline Labour hours reported & $2645,91(\mathrm{~h})$ & $3435,55(\mathrm{~h})$ \\
\hline Annual production quantity & $1056825(\mathrm{pcs})$ per year & $1372475(\mathrm{pcs})$ per year \\
\hline Labour hours reported & $2645,91(\mathrm{~h})$ & $3435,55(\mathrm{~h})$ \\
\hline Labour expenses (Gross+Social tax, per hour) & $6,68 €$ & $6,86 €$ \\
\hline Total annual labour cost & $17675,08 €$ & $23567,87 €$ \\
\hline
\end{tabular}

Table 2. The intended effectiveness of cobot using for labelling operation

\section{Conclusion}

The main goal of this research was to analyse the rationality to substitute an operator's work with a collaborative robot in any working centre. For this purpose, the rationality analysis was conducted, and the general framework of collaborative robots introduction into production was elaborated, which is suitable for all manufacturing enterprises with high mix and low volume production. Cobots implementation was analysed based on a case study at specific Estonian enterprise in cooperation with the manufacturer of robots. The results showed the gains that can support the decision to purchase and implementation of the collaborative robot. The benefits revealed: elimination of manual work and ergonomic issues; provide the future technological advantage of new technology learning; help to increase the financial efficiency and to stay competitive on the market. In future, the research team is planning to perform the effective integration of cobots into the work-cells and to improve the work cells design, which helps in the parts orientation and their smooth processing.

\section{Acknowledgments}

This research is supported by F15027 - Smart manufacturing and materials technologies competence centre.

\section{References}

[1] Krüger, J., Lien, T., Verl, A. (2009) Cooperation of human and machines in assembly lines. CIRP AnnalsManufacturing Technol. 58, 628e646

[2] Hongyi Liu, Lihui Wang (2018) Gesture recognition for human-robot collaboration: A review International Journal of Industrial Ergonomics, Volume 68, November 2018, pages 355-367.

[3] Peschl, M.; Roening, J. \& Link, N. (2012). Human integration in task-driven flexible manufacturing systems, Proceedings of the 23rd International DAAAM Symposium, Volume 23, No.1, ISSN 2304-1382 ISBN 978-3-90150991-9, CDROM version, Ed. B. Katalinic, Published by DAAAM International, Vienna, Austria.

[4] David Greenfield (2019) Choosing Between Cobots and Industrial Robots. AutomationWorlds Conference \& EXPO, pages 14-15. Available from: https://www.automationworld.com/choosing-between-cobots-and-industrial-robots.

[5] Monroe L. (2016) Lean Automation, PalletEnterprice site: http://palletenterprise.com/view_article/4747/Do-Leanand-Automation-Go-Together.

[6] Dennis Kolberg, Detlef Zühlke (2015) Lean Automation enabled by Industry 4.0 Technologies, IFAC-Papers OnLine 48-3 1870-1875, 15th IFAC Symposium on Information Control Problems in Manufacturing INCOM 2015. Available from: https://doi.org/10.1016/j.ifacol.2015.06.359. 
[7] Rajkumar R., Lee I., Sha L, Stankovic J. (2011) Cyber-physical Systems: The Next Computing Revolution. Proceedings of the Design Automation Conference 2010, Anheim, CA, US, pages 731-736.

[8] L.Monostori; B.Kádár; T.Bauernhansl; S.Kondoh; S.Kumara; G.Reinhart; O.Sauer; G.Schuh;W.Sihn; K.Ueda (2016) Cyber-physical systems in manufacturing, CIRP Ann.-Manuf. Technol., vol. 65, no. 2, pp.621_641. doi.org/10.1016/j.cirp.2016.06.005.

[9] V. Rudtsch, J. Gausemeier, J. Gesing, T. Mittag, S. Peter, (2014) Pattern-based Business Model Development for Cyber-Physical Production Systems, Procedia CIRP. 25 313-319. doi:10.1016/j.procir.2014.10.044.

[10] Womack JP, Jones DT, Roos D (1991) The machine that changed the world: the story of lean production. Harper Collins, New York.

[11] Giulia Bruno, Dario Antonelli (2018) Dynamic task classification and assignment for the management of humanrobot collaborative teams in workcells, The International Journal of Advanced Manufacturing Technology, https://doi.org/10.1007/s00170-018-2400-4.

[12] Korn D. (2005) Is Robotic Automation Becoming Practical For Low-Volume Production? Available from: https://www.mmsonline.com/articles/is-robotic-automation-becoming-practical-for-low-volume-production.

[13] David Greenfield (2019) Choosing Between Cobots and Industrial Robots. AutomationWorlds Conference \& EXPO. Available from: https://www.automationworld.com/choosing-between-cobots-and-industrial-robots.

[14] Milton Keynes (2010) Why the time is right to consider robots for low volume processes. ABB Robotics UK Engineering An Automation Nation, Mechanical or Industrial Engineering, United Kingdom. Available from: https://www.linkedin.com/pulse/why-time-right-consider-robots-low-volume-processes-abb-robotics-uk.

[15] Krüger J., Lien T. K., Verl A. W. (2009) Cooperation of human and machines in assembly lines. CIRP Annals Manufacturing Technology 58(2).doi:10.1016/j.cirp.2009.09.009.

[16] Market Research Report SE 4480 (2018) Collaborative Robot Market by Payload Capacity (Up to 5 Kg, Between 5 and $10 \mathrm{Kg}$, Above $10 \mathrm{Kg}$ ), Industry (Automotive, Electronics, Metals \& Machining, Plastics \& Polymers, Food \& Beverages, Healthcare), Application, and Geography - Global Forecast to 2025. Available from https://www.marketsandmarkets.com/Market-Reports/collaborative-robot-market-194541294.htm.

[17] Robert C.V Tai (2015) Collaborative Robots, the Rise of a New Generation. Available from: https://www.myforesight.my/2015/07/28/robert-cv-tai.

[18] Giulia Bruno, · Dario Antonelli (2018) Dynamic task classification and assignment for the management of humanrobot collaborative teams in workcells, The International Journal of Advanced Manufacturing Technology. https://doi.org/10.1007/s00170-018-2400-4

[19] T. Reisinger (2014) Robotics \& manufacturing group presentation. ABB internal presentation,

[20] Kuts V., Sarkans M., Otto T., Tähemaa T. (2017) Collaborative Work Between Human and Industrial Robot In Manufacturing by Advanced Safety Monitoring System. Proceedings of the 28th DAAAM International Symposium, Vienna, Austria, B. Katalinic (Ed.), doi: 10.2507/28th.daaam.proceedings.

[21] Kuts V., Otto T., Tähemaa T, Bukhari K, Pataraia T. ( 2018) Adaptive Industrial Robots Using Machine Vision. ASME International Mechanical Engineering Congress and Exposition, Volume 2: Advanced Manufacturing. doi:10.1115/IMECE2018-86720.

[22] Mahmood K., Karaulova T., Otto T., Shevtshenko E. (2017). Performance Analysis of a Flexible Manufacturing System (FMS). Procedia CIRP, 63, The 50th CIRP Conference on Manufacturing Systems, May 2017, Taiwan, pages 424-429. Available from: https://www.sciencedirect.com/science/article/pii/S2212827117302706.

[23] David Greenfield (2017) Choosing Between Cobots and Industrial Robots, Automation World. Available on https://www.automationworld.com/choosing-between-cobots-and-industrial-robots.

[24] W. Bauer, (2016) Lightweight robots in manual assembly - best to start simply! Stuttgart: Fraunhofer-Institut für Arbeitswirtschaft und Organisation IAO

[25] Askin, R.G. \& Standridge, C.R. (1993 ) Modeling \& Analysis of Manufacturing Systems, John Wiley \& Sons.

[26] Karaulova, T.; Shevtshenko, E. (2015) Work-Cells Concept Development for High Mix Low Volume Market Conditions. Proceedings of the 26 th DAAAM International Symposium,Vienna, Austria, B. Katalinic (Ed.),. Elsevier Procedia Engineering (90-99). doi.org/10.1016/j.proeng.2015.01.346.

[27] D. Battini, X. Delorme, A. Dolgui, and F. Sgarbossa (2015) Assembly line balancing with ergonomics paradigms: two alternative methods. Information Control Problems in Manufacturing (IFAC) Symposium on, vol. 48 (3), pages 586-591.

[28] Fabio Pini, Matteo Ansaloni, Francesco Leali (2016) Evaluation of operator relief for an effective design of HRC workcells, IEEE 21st International Conference on Emerging Technologies and Factory Automation (ETFA), doi: 10.1109/ETFA.2016.7733526

[29] Time study in Production and Operation Management. Available from: https://www.wisdomjobs.com/euniversity/production-and-operations-management-tutorial-295/time-study-9661.html

[30] Mark Lewandowski (2018), User Experience with Collaborative Robots -Procter \& Gamble. National RobotSafety conference 2018. Available from: https://www.robotics.org/userAssets/riaUploads/file/03-UserPanelHoweWeImplentedCollaborativeRobots-MarkLewandowski.pdf.

[31] M Maleki, E Shevtshenko, V Cruz-Machado (2013) Comparative Analysis of Customer Value Dimensions, Engineering Economics, Vol. 24, No.5, pp. 488-495. 